\title{
New Roles for a Changing Environment: Implications of Open Access for Libraries
}

\section{Krista D. Schmidt, Pongracz Sennyey, and Timothy V. Carstens}

This article examines the likely implications of open access on library operations. The context of the examination takes place assuming that the traditional model of publication and open access coexist. Open access presents numerous challenges and opportunities, but entrepreneurial libraries will find new ways to serve their patrons in the new mixed openaccess-traditional (MOA) environment. In order to do so, these libraries will need to redesign their organization and this can be expected to stretch both monetary and human resources.

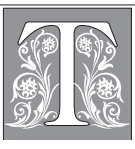

he open-access initiative is a revolutionary movement in scholarly communication that has gathered considerable momentum in the past few years. Open access has many passionate supporters because of its promise to make scholarly information more readily available, slow the commercialization of scholarly communication, and reduce the cost of scholarly publications. The open-access initiative has been at the forefront of countless discussions regarding the future of scholarly communication because open access promises to transform the future. ${ }^{1}$ This transformation will affect libraries as well because they play a critical role in the scholarly communication process.

Libraries intent on providing access to scholarly information cannot afford to ignore open-access venues. In order for libraries to be proactive rather than reactive to the changes open access will bring, a closer examination of the current and impending changes is imperative. The authors of this article recognize that open access has the potential to affect the entire chain of scholarly communication; however, this article explores the effects of open access on libraries only.

\section{Open Access Defined}

Although various definitions of open access have been put forth by interested groups and entities, ${ }^{2}$ for the purposes of this paper, the term open access refers to full-text scholarly articles made completely free and unrestricted to all users to read, copy, download, and distribute over the World Wide Web. Open access

Krista D. Schmidt is a Reference Librarian/Science Liaison at Western Carolina University; e-mail: kschmidt@email.wcu.edu; Pongracz Sennyey is Head of Collection Management Services at the University of Vermont; e-mail: Pongracz.Sennyey@uvm.edu. Timothy V. Carstens is Head of Cataloging/Acquisitions at Western Carolina University; e-mail: carstens@email.wcu.edu. 
can be achieved in a number of ways. The Budapest Open Access Initiative (BOAI) outlines two strategies: self-archiving (referred to as BOAI-I) and open-access journals (BOAI-II). ${ }^{3}$ In BOAI-I, authors place their refereed articles in an open, freely accessible online archive. In BOAI-II, authors publish their articles in open-access journals that do not charge subscription/access fees to readers nor limit accessibility by invoking copyright restrictions (the author retains copyright). By contrast, the traditional model of publication relies almost solely on publishing in journals wherein the user/reader buys a subscription to access the scholarly information contained within the journal. Access is limited to those entities (groups and individuals) that pay subscription costs. Moreover, authors surrender copyright to the publisher upon acceptance of the article for publication.

\section{The Scenarios}

To understand the effects of open access on libraries, the likelihood and degree of success of the open-access movement need to be considered. There has been much debate about if and to what extent the open-access movement will succeed. The potential future of the movement can be addressed in three broad scenarios. In the first scenario, open access fizzles out and fails; in the second, it succeeds by completely surmounting the current subscription model; in the third, it succeeds partially and coexists with the traditional subscription model.

\section{Scenario 1: The Movement Fizzles Out}

In the first scenario, the open-access movement fizzles out after the current enthusiasm wanes. There are several possible reasons for this, including the perception on the part of authors that the open-access movement is not in their best interest. This is critically important because it is largely authors, through their decision to publish in open-access venues, who will determine the success of the movement. Authors may resist the move- ment because the prevalent funding model shifts the cost of the publication to them (generally referred to as the author-pays model). The perceived lack of prestige of open-access journals and repositories also may contribute to authors foregoing open-access options. ${ }^{4}$ In this scenario, the movement basically dies because authors and institutions, more comfortable with the traditional model, fail to embrace the open-access movement.

This scenario seems unlikely for a number of reasons. It assumes that authors will not take advantage of the opportunities made available by open access, such as authors' retention of copyright, rapid dissemination of research, and impact advantage. ${ }^{5}$ Moreover, the demise of the open-access model would mean that governments, grant-funding agencies, and universities passively continue to support the profit margins of commercial publishers. Because funding agencies generally desire the results of funded research to be widely disseminated, some of them have seriously considered the possibility of requiring authors to publish research articles they fund in open-access venues. ${ }^{6}$ Based on these two factors alone, the supposition that the open-access movement will fail and disappear from the scene seems unrealistic.

\section{Scenario 2: The Movement Is an Over- whelming Success}

In the second scenario, open access succeeds so overwhelmingly that the traditional subscription model succumbs to its advantages and disappears. Researchers en masse no longer agree to sign away the rights to their work for someone else's profit, refuse to accept the traditional lag time from finished research to published paper, and reject the current boundaries that limit dissemination of important and timely information. In addition, organizations and funding agencies refuse to continue to subsidize the nonstop inflationary burden imposed by the traditional model.

Although this scenario would appeal to many individuals and organizations, it 
also seems unlikely to happen. Although both authors and institutions may be ready to take advantage of open access, the fact that the traditional model is well established and reputable is likely to keep the open-access movement from completely succeeding. For example, publications such as Brain, Biochimica et Biophysica Acta, and Cell currently enjoy the advantage of a long record of publication and a reputation for publishing the highest-quality research in their fields. The superior reputation of such leading journals almost guarantees they will continue to find authors who are high-quality scholars as well as customers who are willing to pay to read this research.

Moreover, devising a sustainable and affordable model to fund open-access serials remains unresolved. Although the evidence suggests that open-access publications are considerably less expensive to fund than the traditional subscription model, journals in some disciplines such as the humanities and social sciences remain very inexpensive. ${ }^{7}$ The open-access model cannot dislodge these titles merely on the basis of a cost advantage. Given all these factors, the existence of open access should not be interpreted as the inevitable demise of the traditional model.

\section{Scenario 3: The Movement Is a Mixed Success}

In this scenario, the open-access movement will continue to succeed but will not cause the complete eradication of the traditional model. Instead, both the open-access and the traditional publishing models will compete for authors and resources concurrently. In many ways, this is the present situation: both openaccess venues and subscription journals coexist.

Many reasons suggest that this scenario is likely to endure. The traditional publication model has many players that have a vested interest in its continuation. In addition, this model reaps ample profits, which help to keep it functional. Commercial, academic, and other publishers may have to change their pricing structure, improve efficiency, and tweak operations, but there is little reason to believe they do not have the necessary flexibility to compete with open access. Also, the attraction of well-established titles will remain in place and such titles will continue to attract high-caliber authors, despite the growing respect afforded to some open-access journals. On the other hand, open access offers new and less restrictive publishing venues for scholars. In addition, some funding agencies require that research performed with their funds be published or made accessible in open-access forums. Open access may prove to be a healthy catalyst for change, rather than serving as the device that topples the entire traditional publishing edifice

\section{Mixed Open-Access Success and Its Effects on Libraries}

As illustrated above, it appears that scenarios one and two are unlikely to take place whereas the third scenario, called mixed open access (MOA), is already beginning to take place. For example, universities such as CalTech, Boston College, and MIT have created institutional repositories for faculty wherein preprints, postprints, and data sets may be found; open-access journals are indexed in premier databases such as PubMed, PsycInfo, and Chemical Abstracts; and some university libraries are beginning to include items such as the DOAJ or preprint servers such as ArXiv (physics) in their list of resources. ${ }^{8}$ It is too early to determine to what degree the traditional publishing model and open access will coexist. Will this environment still heavily favor traditional publishing, or will a more equitable mixture become the norm? The proliferation of open-access journals and repositories in conjunction with the continued existence of traditional venues has many implications, and examining how MOA affects libraries is of critical importance now.

The most dramatic challenge that open-access resources present to librar- 
ies is the fact that these resources do not require the patrons to use the library. Patrons may go to the Web and simply use the open-access resource, completely bypassing the library. This is a striking contrast to the situation that existed when libraries built a physical collection of resources that required patrons to come to the library to use them. In the electronic era, patrons do not have to come to the library for many resources, yet they rely on remote electronic resources that libraries select and fund and to which libraries provide access. The advent of the Internet and search engines such as Google has eroded patrons' reliance on libraries by making it possible for patrons to find large quantities of information, especially the sort referred to as "ready reference," without using the library. Similarly, open access makes another large, yet more scholarly, class of materials available for free on the Web, bypassing the library to find an ever-growing proportion of the available information on the Web. In this way, libraries could lose their central place in the scholarly research process.

MOA also presents opportunities for libraries to look beyond their traditional roles of building collections and subscribing to remote resources. Libraries need to think of themselves as mediators between their patrons and the ever-expanding and increasingly complex world of information. With regard to open-access resources, libraries can serve their patrons in a number of ways. Patrons may be unaware of the existence of openaccess resources, so librarians can assist them by identifying the resources that meet patron needs. One way this can be accomplished is by providing patrons with indexes and databases that include open-access resources. For example, EBSCOhost recently began providing access to selected Directory of Open Access Journals (DOAJ) titles. Another respected database, PubMed, indexes select open-access journals as well. It is certain that more indexing and abstracting services will follow suit.
Despite the likelihood that more indexers and aggregators will add open-access resources to their databases, libraries should not passively rely on them to include these titles. As with traditional journals, librarians must be aware of what open-access resources are included in any particular database. Libraries also must maintain communication with aggregators so that they know the aggregators' inclusion policies and how aggressively a particular aggregator searches for and includes open-access items. The overlapping and fluctuating coverage of traditional resources provided by indexers and aggregators already provides ample reason for libraries to evaluate what they buy more carefully, but the advent of the MOA environment makes this task urgent and complex. Moreover, libraries cannot rely on indexers and aggregators to lead their patrons to every relevant open-access resource. It is likely that some open-access journal titles will not be included by any indexer or aggregator. For example, Magnetic Resonance in Solids, Electronic Journal is a peer-reviewed electronic journal pertaining to basic research in magnetic resonance of solids and related phenomena and it is not indexed in the DOAJ, the most likely database to contain any openaccess title. Yet, this item may still be of interest and use to patrons; it is obvious that libraries must take the initiative to add it to the library catalog themselves. Indexers and aggregators may be less likely to provide access to the information in institutional or discipline-based open-access repositories. Because some of the most cutting-edge information is included in these resources, a concerted effort must be made to alert patrons to these open-access venues. Librarians will have to work hard to identify these important and useful resources.

Another challenge for libraries operating in an MOA environment is to monitor the quality of the open-access resources to which their patrons are directed. Even a relatively "respectable" list of open-access journals such as DOAJ will include jour- 
nals of widely differing quality in terms of both content and editorial control. Librarians should identify a specific open-access journal as a high-quality product before directing their patrons to it. In fact, as with print journals, the question of quality continues to be an issue. Although many open-access publishers are striving to retain a stringent peer review or editorial component within their publication process, open access is still a new publication model. Some also argue that the prevailing author-pays model provides less incentive for open-access publishers to apply rigorous quality control standards. ${ }^{9}$ The issue of quality is even more critical in the case of discipline-based, institutional and, in particular, personal repositories. Although most disciplinebased and institutional repositories have policies or guidelines in place that govern what types of materials are acceptable for submission, there are no controls or rules to dictate what types of resources may be included in an individual's personal repository. In theory, anyone could make any type of material, both quality and not, available on the Web via a repository.

Meeting the implications of MOA also will mean more work for bibliographers. In the MOA environment, bibliographers will have to work as diligently as ever to identify, evaluate, and select those resources that should be purchased with library funds. Moreover, they will be responsible for identifying open-access resources that will be of interest to their patrons. In addition, bibliographers will be responsible for finding the repositories that need to be included in the library's catalog, database lists, and so on. To do these things effectively, bibliographers must stay abreast of trends in their disciplines and maintain an awareness of how each discipline views and uses open-access items. To keep track of openaccess venues, bibliographers need to use open-access-specific tools or databases such as DOAJ (http://www.doaj.org/), OAIster (http://oaister.umdl.umich.edu/ o/oaister/), Sherpa's "Publisher copy- right policies \& self-archiving," as well as tools such as Google's Open Access Resources Directory (http://directory. google.com/Top/Reference/Open_Access_Resources/) or the Google Scholar platform (http://scholar.google.com/). In addition, sometimes bibliographers must simply surf the Web for this information. These tools will help bibliographers to make decisions about what items should be used or included, recommended or not recommended, based on the discipline. This will be even more challenging and time-consuming if open-access publications and venues continue to multiply at their current rate.

Although identifying high-quality open-access resources is critically important, these resources will not be useful to patrons unless libraries communicate their existence and usefulness and integrate them into their virtual collections. Librarians can alert patrons to open-access venues in a number of ways, including adding an open-access resource in the library catalog or to the library's list of serials. When open-access resources are included in the catalog, patrons will not need to wonder whether the material is available in a traditional print or electronic subscription or via open access. The catalog can provide them with just one place to look for this information. Librarians also should include appropriate open-access resources in pathfinders and research guides because these are other important ways of directing patrons to relevant, high-quality information.

When open-access resources have been included in the library catalog and other library products, the information about these resources must be maintained. The difficulty of maintaining open-access resources in the library catalog and other resources should not be underestimated. To begin, it is reasonable to assume that open-access journals will be at least as prone to name changes, splits, mergers, URL changes, changes in subject coverage, and cessation as their print subscription counterparts. It also seems likely that 
repositories of all types may be subject to similarly frequent transformations. The catalog and other library resources will need to be updated regularly to reflect these changes.

Open-access resources also share with other electronic publications a host of characteristics that make them difficult to maintain in the catalog. The challenge of maintaining the currency of URLs, which are prone to change or disappear, should be obvious. Libraries are attempting to deal with this problem locally through the use of link checkers and collectively by means of the CONSER PURL (Persistent Uniform Resource Locators) project. ${ }^{10}$ Dealing with title changes in electronic journals also has proved to be a problem. With print publications, changes in title and so on are caught when an issue is checked in and a cessation is caught when an issue fails to arrive. Electronic subscriptions offer fewer routine methods of catching these changes. Even greater problems can occur when electronic publishers, both traditional and open access, decide to change the title of a journal and then apply that title change to all the earlier issues of the title on their Web site. Should the cataloger use successive cataloging entry (entry under each title the journal has had) or latest-entry cataloging (entry under the last title) to handle such a journal? Although it is tempting to treat this type of journal as an integrating resource and use latest-entry cataloging, the survival of the earlier title in patron citations and in article-level running titles and so on presents problems for this approach as well. ${ }^{11}$ The simultaneous existence of multiple formats of the same journal, including print and microform and different electronic journal file formats and aggregator versions, creates additional troubles. ${ }^{12}$ The question of how to provide the necessary information about these multiple versions and the relationships among them without thoroughly confusing the patron continues to be a problem for the cataloging profession. Finally, ensuring that the catalog contains accurate ISSN information for electronic journals has become an important challenge. ISSN numbers have become a critical piece of information because they are often used by various technologies to link databases to the online catalog and to each other. However, journals that lack ISSN or have different ISSNs for different formats can make the provision and maintenance of the appropriate version of these important identifiers difficult. ${ }^{13}$

All the difficulties of adding electronic resources to the catalog apply to open-access journals as well, and these resources are likely to present additional unique problems. Electronic journals purchased by subscription are not checked in, bound, or handled physically in the same way that print journals are, but they still require attention from library staff because licenses must be negotiated and renewed, passwords or IP ranges tested, and authentication software maintained. All these processes provide the library the opportunity to evaluate the availability and scope of these titles and ensure that bibliographic information such as the title continues to be accurate. In contrast, libraries only have to link to open-access titles once. In this way, open-access resources are somewhat like free Web sites. When they are in a library catalog or other finding aid, they can easily morph into other forms without the library's knowledge. Therefore, to maintain these resources properly, libraries will need to adopt mechanisms that regularly check these resources to ensure that the information provided is up to date and accurate. This active maintenance routine is bound to be more complex and time-consuming than the more passive methods that have worked for more traditional resources.

The open-access business model also may not give publishers incentive to actively cooperate with the library or with serials vendors who may be acting on behalf of groups of libraries. Libraries are one of the most important customers under the traditional subscription model, and so journal publishers have an inter- 
est in making their publications easy for libraries to use. With authors as their customers, open-access arrangements may not have the same incentive to cooperate. For example, will open-access journal publishers have the same incentive to work with libraries to solve problems such as changed titles, URLs, cessations, and downtime that sometimes affect electronic journals? The need for some kind of relationship between publishers and libraries, though perhaps not as critical, will still be necessary in an open-access environment.

The hybrid character of the MOA environment presents other serial maintenance challenges for the library. A library might contain parts of the same journal in print and microform, provide access to a part of the journal's back file through an open-access archive, and provide access to issues through an aggregator. Access for a particular resource may undergo constant change as license agreements are renegotiated, embargoes are put into effect, and publication strategies evolve. Keeping up with this constant change, while making all these variations in access transparent to the patron, is an additional maintenance challenge for the library.

Another factor that may increase the difficulty of serials maintenance in the MOA environment is the increase in the number of titles that must be maintained. In the print/electronic subscription environment, the number of titles is limited by the library's budget. In the MOA environment, libraries will have to maintain both their paid subscription titles and every open-access title added to the catalog. Because libraries do not pay for open-access titles, there is no fiscal limit to the number of titles that can be added. Therefore, as the number of open-access resources grows, the library may find itself keeping track of many more openaccess titles than subscription titles. This will obviously increase the workload of serials maintenance. An increase in the number of serial titles also may result in an increased need for products such as federated search engines and open URL link resolvers. These can help the patron more easily navigate among resources of a large and complex MOA environment. However, these products also generate maintenance issues of their own because they rely on complex database tables containing detailed information about every title and database of concern to the library. These tables require regular and extensive maintenance.

The maintenance involved with providing patrons access to MOA resources will be a daunting challenge for libraries. However, there are some ways in which open-access resources will require less maintenance than traditional subscription resources. Open-access journals do not require subscription funds or license agreements. Libraries do not have to check in or claim these publications to ensure that they have received what was promised. Furthermore, unlike print materials, libraries do not have to physically process, shelve, bind, or withdraw these resources. The resources saved by not having to perform these tasks could be directed toward the new tasks associated with MOA.

By making open-access resources available through the library catalog and other resources, the library will be able to make the MOA environment almost transparent to the patron. MOA also has significant implications for public services librarians. Most library patrons currently are unaware of the wealth of information available in the open-access environment. This is an important gap that information literacy instruction can fill. As their awareness increases, patrons will expect librarians to be able to help them navigate a chaotic and complex MOA environment. They are especially likely to need help using open-access repositories if they have not previously used these resources. Patrons also are likely to need help evaluating the quality of open-access information because quality can be uneven. In order to fulfill this role effectively, public services librar- 
ians will have to become educated about open access. Bibliographers, who should be actively investigating open access in their disciplines, will have a role to play in this training process.

As a result of their traditional role as storehouses of scholarly information, libraries have a natural role in the creation and operation of institutional repositories. Although responsibility for managing campuswide policies and procedures, managing the computational and technical requirements of repositories, and exercising editorial and quality control is unlikely to fall to libraries alone, libraries can be responsible for some repository tasks. For example, it is natural for the library to assume responsibility for organizing the information within the institutional repository. The Open Archives Initiative Protocol for Metadata Harvesting provides one framework for organizing information within repositories. ${ }^{14}$ Librarians also may play an administrative role. For instance, because of their experience with copyright issues, librarians are well suited to assist authors in obtaining permission to include previously published materials in the repository. These natural relationships foster a close association between the library and an institutional repository.

The library's involvement in the operation of institutional repositories suggests another new role. Institutional repositories and open-access venues in general are having some difficulty attracting authors to publish on their sites. ${ }^{15}$ One role that libraries may assume is to encourage open-access publication by subsidizing authors' fees in open-access venues. Some trailblazing libraries have already begun to fund open-access publication. ${ }^{16}$ Funding open-access publication is a new twist on the library's traditional role as the institutional purchaser of scholarly information. In addition, this funding role will help keep the library at the center of the scholarly enterprise. As an added benefit, encouragement of open-access publication with library subsidies may add pressure on commercial publishers to control their price increases. However, subsidizing authors' publication costs also may be risky for libraries because libraries may not receive any additional funding to cover the cost of this activity. In this case, these subsidies will have to be funded with money that would otherwise be used to build library collections.

The overall effect of MOA on library budgets is uncertain at this point. The number of both monographs and subscription-model serials being published continues to increase. At the same time, both monograph and serial inflation continues at a rate higher than the CPI, while library collection budgets remain flat. If libraries begin to subsidize open-access publication, this will create yet another strain on the budget. These trends are a real threat to the ability of the library to operate within its financial constraints. But, if open access becomes a catalyst for change and subscription costs decrease, the potential benefits are obvious. This would be a great benefit to libraries because serials inflation has done more damage to library budgets than any other trend. If serials costs decrease, libraries should take steps to repair the damages that decades of unchecked inflation have wrought on collections. Monographs, audiovisuals, data sets, and primary sources are long-neglected parts of library collections. Those libraries that succeed in addressing these problems are sure to make themselves more relevant to their patrons.

\section{Conclusions}

The evidence suggests that although open-access sources are multiplying at a rapid pace, the traditional model will not disappear. In all likelihood, the traditional model will coexist with the open-access model for years to come. This is especially true of journals in the humanities and social sciences, which are moderately priced and are competitive with the openaccess model from a financial perspective. The implications for libraries and their 
organization are significant. The fact that open-access resources are accessible without the library's intervention suggests that academic libraries will have to reconsider strategies to remain relevant to their patrons.

It is evident that library operations were built on a paradigm of scholarly communication based on printed sources. With the onset of electronic publications, and now open-access publications, this paradigm is bound to change. It is obvious that the changes in scholarly communication will force libraries to change as well. This article is not meant to focus on the difficulties and uncertainty of a changing environment but, rather, to alert the profession to the opportunities and challenges these changes will bring. Although many of the issues described above have been present in libraries since the advent of electronic publications and the Internet, the emergence of the openaccess movement exacerbates the urgency of issues such as archiving, data stability, cost containment, and so on.

Finally, it is worth noting that the emergence of the open-access initiative shatters the myth that there are no alternatives to the traditional publishing model. What libraries do with the opportunities that the open-access movement offers will depend on librarians' resourcefulness and creativity. And, in this sense, the changes open access elicits are empowering.

\section{Notes}

1. Pritpal S. Tamber, Fiona Godlee, and Peter Newmark, “Open Access to Peer-reviewed Research: Making It Happen," Lancet 362, no. 9395 (Nov. 8, 2003): 1575-77; Brian D. Crawford, “Open-access Publishing: Where Is the Value?" Lancet 362, no. 9395 (Nov 8, 2003): 1578-80; David Malakoff, "Scientific Societies Lay Out 'Free Access' Principles," Science 303, no. 5666 (Mar. 26, 2004): 1959; Stevan Harnad, "Debate Over Open Access in the U.K.," Science 306, no. 5705 (Dec. 24, 2004): 2187; Ajit Varki, “Open Access: The JCI Has Already Shown It Works," Nature 426, no. 6965 (Nov. 27, 2003): 383.

2. Some examples include the Berlin Declaration (http://www.zim.mpg.de/openaccess-berlin/berlindeclaration.html), the Washington DC Principles for Free Access to Science (http://www. dcprinciples.org/statement.pdf), the Bethesda Statement on Open Access Publishing (http://www. earlham.edu/ peters/fos/bethesda.htm), and Wellcome Trust Position Statement in Support of Open Access Publishing (http://www.wellcome.ac.uk/doc_WTD002766.html).

3. Open Society Institute, "Budapest Open Access Initiative." Available online at http://www. soros.org/openaccess/read.shtml.

4. Carol Cruzan Morton, "Experts Debate Open-access Publishing Option," Focus (Jan. 9, 2004), under "Publishing" at http://focus.hms.harvard.edu/2004/Jan9_2004/publishing.html; "Public Library of Science Launches PLoS Biology: New Open-access Journal Will Increase Access to Scientific Research and Speed Scientific Discovery," ScienceDaily (Oct. 14, 2003). Available online at http://www.sciencedaily.com/releases/2003/10/031014072453.htm.

5. Steven Harnad and Tim Brody, "Comparing the Impact of Open Access (OA) vs. NonOA Articles in the Same Journals," D-Lib Magazine 10, no. 6 (June 2004). Available online at doi:10.1045/june2004-harnad, http://www.dlib.org/dlib/june04/harnad/06harnad.html; Open Society Institute “Budapest Open Access Initiative," Feb. 14, 2002. Available online at http://www. soros.org/openaccess/read.shtml.

6. "Scientific Publishing Is Having to Change Rapidly to Respond to Growing Pressure for Free Access to Published Research," Economist 372, no. 8387 (Aug. 7, 2004): 65.

7. SQW Limited, preface to Costs and Business Models in Scientific Research Publishing: A Report Commissioned by the Wellcome Trust. (London: The Wellcome Trust, 2004), iii; available online at http://www.wellcome.ac.uk/en/images/costs_business_7955.pdf; Donald W. King, "Should Commercial Publishers Be Included in the Model for Open Access through Author Payment?" D-Lib Magazine 10, no. 6 (June 2004). Available online at doi:10.1045/june2004-king, http://www.dlib. org/dlib/june04/king/06king.html.

8. Two examples include Cornell University, which lists both DOAJ and ArXiv.org in the general and physics database lists (http://encompass.library.cornell.edu:20028/index.html) as well as the University of North Carolina-Chapel Hill, which includes DOAJ in "Article Databases \& More" (http://eresources.lib.unc.edu/eid/list.php?letter=D) and ArXiv.org in a research guides 
for physics (http://www.lib.unc.edu/brauer/physguide.html).

9. Michael A. Mabe, "Peer Review and Pay-to-Publish: The World Turned Upside Down?" Against the Grain 16, no.3 (June 2004): 56. 323.

10. Emily McElroy, "An Interview with Steve Shadle," Serials Review 28, no.4 (winter 2002):

11. Les Hawkins, "Reflections on Wrapping Paper: Random Thoughts on AACR2 and Electronic Serials," Serials Review 30, no.1 (2004): 53.

12. _— "An Interview with Jean Hirons, CONSER Coordinator," Serials Review 29, no.3 (fall 2003): 234-35.

13. Marian Shemberg, "The Role of the ISSN in the Electronic Linking Environment," Serials Review 29, no.2 (summer 2003): 89-96.

14. Carl Lagoze, ed., et al, "The Open Archives Initiative Protocol for Metadata Harvesting," Mar. 21, 2003. Available online at http://www.openarchives.org/OAI/openarchivesprotocol. html\#Repository.

15. Andrea L. Foster, "Papers Wanted: Online Archives Run by Universities Struggle to Attract Material," Chronicle of Higher Education (June 25, 2004).

16. OhioLink, "Ohio Academic Libraries Support Public Library of Science: OhioLINK Will Fund Half of PLoS' Publication Fee for Authors at 85 Institutions," news release, June 2, 2004. Available online at http://www.ohiolink.edu.

\section{Elegant Solutions for Preservation}

Call for a complete catalog

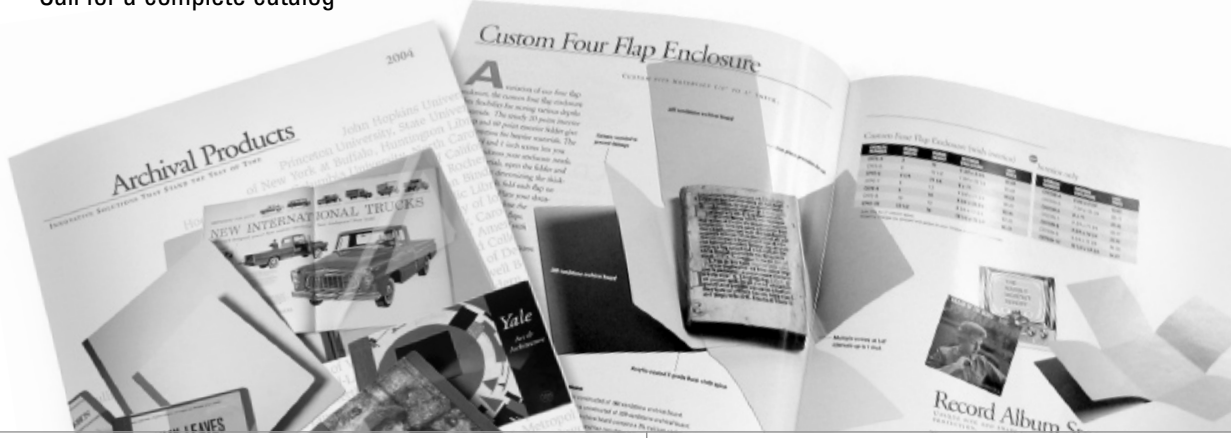

Pamphlet Binders

Music Binders

Archival Folders

Manuscript Folders

Hinge Board Covers

Academy Folders

Newspaper/Map Folders

Polypropylene Sheet \&

Photo Protectors

Conservation \&

Preservation Tapes
Bound Four Flap Enclosures Archival Binders Archival Boards Adhesives Bookkeeper Century Boxes Record Album Enclosures Conservation Cloths
ARCHIVAL PRODUCTS

P.O. Box 1413 | Des Moines, Iowa 50305-1413 800.526.5640 | Fax 888.220.2397 custserv@archival.com | www.archival.com 